\title{
BIMTEK MUTU PRODUK COR BALING-BALING KAPAL NELAYAN HASIL CETAKAN PASIR DENGAN BAHAN DASAR SKRAP ALUMINIUM BAGI IKM DISPERINDAG KOTA PASURUAN
}

\author{
Djoko Andrijono $^{1)}$, Sufiyanto ${ }^{2)}$ \\ ${ }^{1,2)}$ Fakultas Teknik, Universitas Merdeka Malang \\ 1) Email:djoko.andrijono@unmer.ac.id \\ ${ }^{2)}$ Email: sufiyanto@unmer.ac.id
}

\begin{abstract}
Abstrak
Desa Mayangan Kecamatan Panggungrejo Kota Pasuruan merupakan lokasi IKM Pengecoran pembuatan balingbaling kapal nelayan dengan cara melebur skrap aluminium di dalam dapur peleburan selanjutnya dituang ke dalam cetakan pasir kemudian dibiarkan sampai membeku. Temuan masalah dari hasil bimtek meliputi : cacat rongga udara disebabkan penggunaan model cawan tuang dan saluran turun yang langsung digunakan pada cetakan pasir, udara atau gas panas dari cetakan pasir atau logam cair skrap aluminium tidak dapat keluar melalui rongga antara butir-butir pasir saat proses penuangan, pasir sungai berbentuk butir pasir kristal dapat mempengaruhi ketahanan api dan permeabilitas yang buruk pada cetakan pasir akibatnya membutuhkan pengikat dalam jumlah banyak, dan kadar air pada pasir sungai kurang dari 1,5\% - 8\% akibatnya lempung akan mengalami kekurangan daya ikat untuk mengikat pasir sungai. Kesimpulan meliputi : cacat rongga udara dapat dikurangi dengan memasang saluran tuang tipe offset stepped basin agar turbulensi saat penuangan logam cair dapat berkurang, meningkatkan permeabilitas pasir sungai agar udara atau gas panas yang berasal dari cetakan pasir atau logam cair skrap aluminium dapat keluar melalui rongga antara butir-butir pasir saat proses penuangan, butir pasir sungai yang digunakan berbentuk bulat agar kebutuhan pengikat lebih sedikit, sehingga diperoleh kekuatan dan permeabilitas yang optimum serta memperbaiki sifat mampu alir.
\end{abstract}

Kata kunci: Baling-Baling Kapal Nelayan, Cacat Rongga Udara, Cetakan Pasir.

\section{PENDAHULUAN}

\section{a. Analisis Situasi}

Kota Pasuruan merupakan sebuah kota di Provinsi Jawa Timur, Indonesia yang terletak 60 $\mathrm{km}$ sebelah tenggara Surabaya, ibu kota provinsi Jawa Timur dan $355 \mathrm{~km}$ sebelah barat laut Denpasar, Bali. Seluruh wilayah Kota Pasuruan berbatasan dengan Kabupaten Pasuruan. Kota Pasuruan berada di jalur utama pantai utara yang menghubungkan Pulau Jawa dengan Pulau Bali, sehingga kota Pasuruan memiliki prospek ekonomi yang besar di kawasan Indonesia bagian timur (https://id.wikipedia.org/wiki/

Kota_Pasuruan).

Secara geografis Kota Pasuruan tepat di jalur utama transportasi dan perdagangan Surabaya - Bali, menjadikan Kota Pasuruan dengan luas wilayah $36.58 \mathrm{~km}^{2}$ atau sekitar $0,07 \%$ luas Jawa Timur ini cukup strategis memberikan kontribusi pada pergerakan perindustrian dan perdagangan. Batas-batas wilayah Kota Pasuruan yang terletak antara $112^{\circ}$ $45-112^{0} 55$ Bujur Timur dan $7^{0} 35-7^{0} 45$ Lintang Selatan ini meliputi Selat Madura di bagian Utara sedangkan sebelah Timur, Selatan dan Barat berbatas dengan Kabupaten Pasuruan (https://pasuruankota.go.id/geografi/).

Data UMKM dan tenaga kerja di Provinsi Jawa Timur, khususnya Kota Pasuruan memiliki
24.257 UMKM dengan 44.520 tenaga kerja (diskopukm.jatimprov.go.id/viewmedia.php?page $\mathrm{s}=$ content). Klasifikasi industri berdasarkan data Dinas Perindustrian dan Perdagangan Kota Pasuruan 2014 s.d 2017 (Tabel 1).

Tabel 1. Klasifikasi Industri Berdasarkan Data Disperindag Kota Pasuruan

\begin{tabular}{|c|c|c|c|c|c|}
\hline No & Klasifikasi Industri & 2014 & 2015 & 2016 & 2017 \\
\hline 1 & $\begin{array}{lr}\text { Industri Kimia } & \text { Agro } \\
\text { dan Hasil Hutan } \\
(\mathrm{IKAHH})\end{array}$ & 2.348 & 2.320 & 2.358 & 2.307 \\
\hline 2 & $\begin{array}{lr}\text { Industri } & \text { Logam } \\
\text { Mesin } & \text { Elektronika } \\
\text { dan Aneka (ILMEA) }\end{array}$ & 1.361 & 1.496 & 1.548 & 1.682 \\
\hline & Jumlah & 3.667 & 3.709 & 3.709 & 3.989 \\
\hline
\end{tabular}

Sumber: Disperindag Kota Pasuruan.

Industri logam merupakan industri yang sangat berkembang di Kota Pasuruan disamping industri meubel. Sentra industri logam skala kecil dan kerajinan dari logam di Kota Pasuruan berada di Kelurahan Mayangan, Kelurahan Ngemplakrejo dan di sebagian wilayah Kecamatan Gadingrejo yang dikelola secara semi tradisional.

Produk yang dihasilkan telah memiliki kualitas baik dan memenuhi standar kualitas. Pemasaran hasil produksi tidak terbatas di wilayah Jawa Timur melainkan sudah sampai ke luar propinsi. Jenis kerajinan logam yang 
dihasilkan oleh industri kecil antara lain: aksessories mobil dan motor, spare part mobil dan motor, peralatan rumah tangga dan aksesories meubel.

Perkembangan local intellegent oleh pengusaha industri logam mendorong industri ini berkembang menjadi produk komponen roda dua atau empat, mesin diesel, baling-baling kapal atau perahu, perlengkapan pabrik atau industri besar dan mesin perkakas. Tahun 2014, jumlah pengusaha industri logam yang terdapat di Kota Pasuruan sebanyak 410 pengusaha dan tenaga kerja dari industri logam yang dapat diserap mencapai 2.886 orang dengan nilai produksi Rp. 537.619.865,- serta nilai investasi sebesar Rp. 76.703 .315 dengan nilai bahan baku sebesar Rp. 244.470.020,-.

Wilayah pemasaran meliputi: Jakarta, Sumatera, Sulawesi dan ekspor ke Taiwan. Perkembangan industri logam di Pasuruan juga diikuti oleh berdirinya industri besar seperti: PT. Boma Bisma Indra (Persero), Pabrik Tekstil Raindo Lestari dan Busana Jaya maupun perusahaan bengkel lainnya yang turut menciptakan iklim usaha industri logam yang kondusif dan kompetitif di Kota Pasuruan (http://mohammadfachrii.blogspot.com/2017/03/ profil-kota-pasuruan-jawa-timur.html).

Kota Pasuruan secara demografi (kependudukan), masyarakat tergolong heterogen terdiri dari beragam etnis. Empat etnis yang mendominasi meliputi : Jawa, Madura, Tionghoa dan Arab. Etnis Madura lebih banyak mendiami wilayah utara Pasuruan, sedangkan tiga etnis lainnya tersebar di bagian tengah perkotaan. Heterogenitas masyarakatnya tidak lepas dari keberadaan pelabuhan yang menarik minat orang untuk datang dan tinggal di Kota Pasuruan. Mayoritas penduduk Kota Pasuruan memeluk agama Islam dan multi etnis, tetapi hubungan masing-masing berjalan harmonis. Jumlah penduduk kota pasuruan berdasarkan jenis kelamin 2017 (Tabel 2).

Tabel 2. Jumlah Penduduk Kota Pasuruan Berdasarkan Jenis Kelamin 2017

\begin{tabular}{cccc}
\hline Bulan & Laki-laki & Perempuan & Total \\
\hline Januari & 104.784 & 104.433 & 209.217 \\
Februari & 104.944 & 104.549 & 209.493 \\
Maret & 105.088 & 104.706 & 209.794 \\
\hline
\end{tabular}

Sumber: Dispenduk Capil Kota Pasuruan, 2017

Berdasarkan data di atas, tahun 2017 jumlah industri di bawah pembinaan Disperindag Kota Pasuruan sejumlah 3.989 ILMEA, termasuk salah satunya industri pengecoran logam skala industri rumah tangga di desa Mayangan Kecamatan Panggungrejo Kota Pasuruan yang memproduksi seperti: cetakan kue, miniatur sepeda untuk souvenir atau hiasan, mata cangkul, dan sabit. Di samping produk tersebut, juga memproduksi baling-baling (propeller) kapal nelayan terbuat dari logam bukan besi (non ferrous metal) jenis skrap aluminium.

Proses pembuatan baling-baling kapal nelayan di desa Mayangan Kecamatan Panggungrejo menggunakan proses pengecoran (casting process) dengan peralatan penunjang yang sangat tradisionil, seperti: dapur peleburan untuk proses peleburan bahan baku (logam), ladel untuk proses penuangan logam cair ke dalam cetakan pasir, cetakan pasir untuk membuat produk cor jenis baling-baling, rangka cetak dari material kayu untuk memperkokoh dinding cetakan akhir. Langkah-langkah proses pengecoran yang dilakukan oleh IKM logam, khususnya IKM pengecoran logam meliputi: penyiapan logam cor jenis pencairan logam skrap aluminium (Gambar 1), pembuatan cetakan pasir (sand moulding) (Gambar 2), penyiapan matras atau pola (pattern) terbuat dari bahan kayu meranti sesuai dengan bentuk produk balingbaling, proses peleburan aluminium skrap pada dapur peleburan dengan bahan bakar gas (Gambar 3), proses penuangan logam cair menggunakan ladel (Gambar 4), proses pembongkaran hasil cor dengan cara merusak dinding cetakan pasir (Gambar 5), dan produk cor baling-baling setelah proses pengerjaan akhir (Gambar 6) dengan menggunakan gerinda listrik.

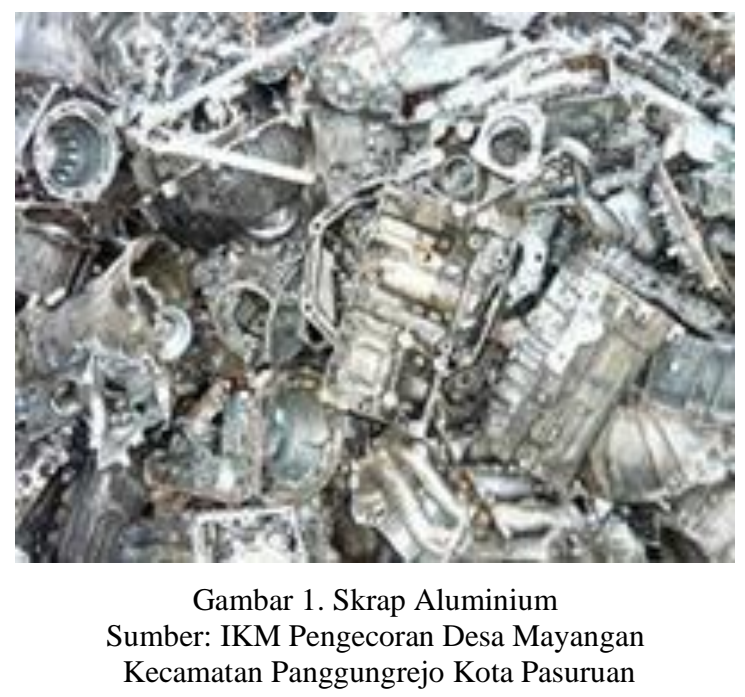




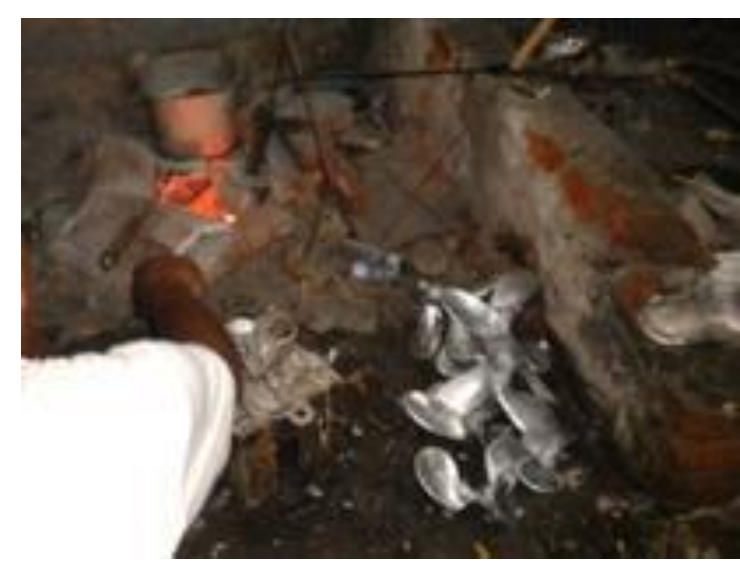

Gambar 3. Peleburan Skrap Aluminium Pada Dapur Peleburan

Sumber: IKM Pengecoran Desa Mayangan Kecamatan Panggungrejo Kota Pasuruan

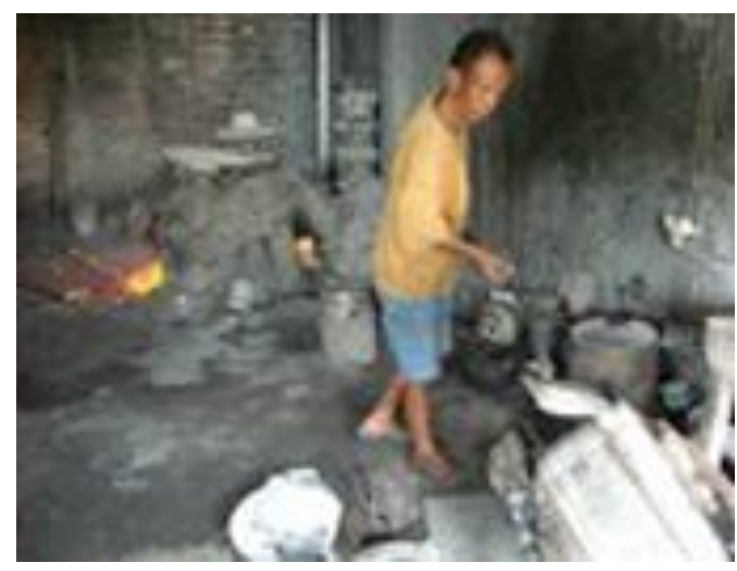

Gambar 4. Proses Penuangan Logam Cair Skrap Aluminium Ke Dalam Cetakan Pasir Sumber: IKM Pengecoran Desa Mayangan Kecamatan Panggungrejo Kota Pasuruan

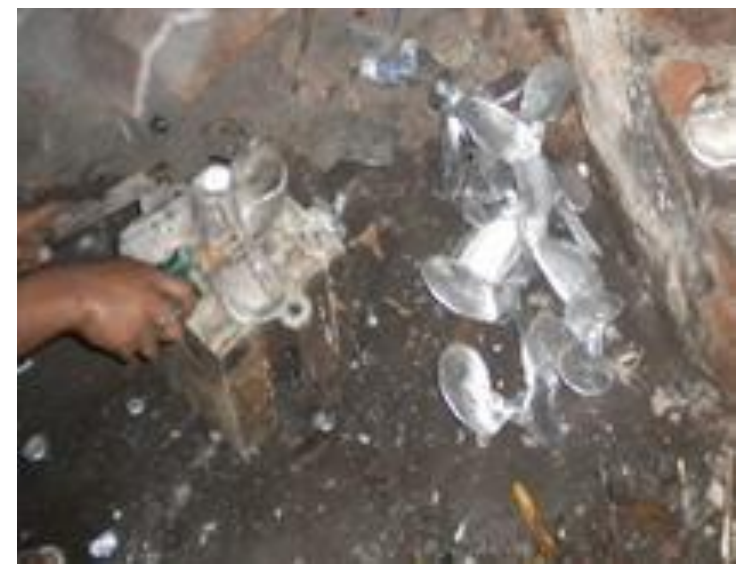

Gambar 5. Proses Pembongkaran Hasil Cor Baling-Baling Kapal Nelayan dari Cetakan Pasir

Sumber: IKM Pengecoran Desa Mayangan Kecamatan Panggungrejo Kota Pasuruan

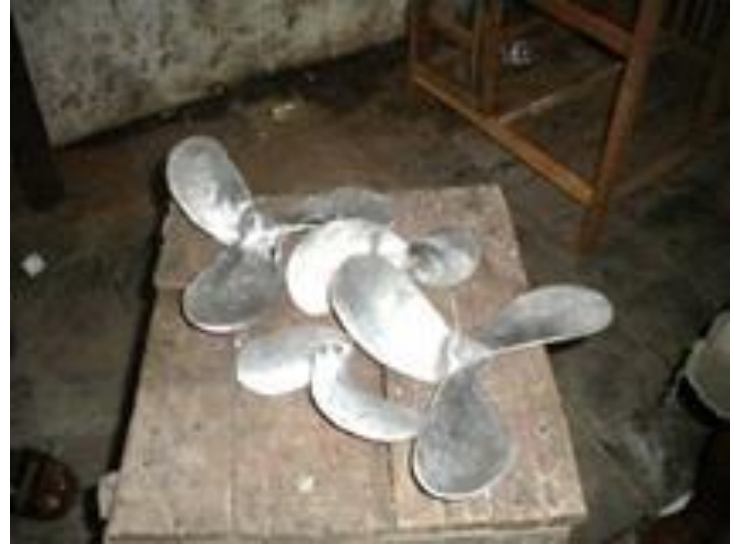

Gambar 6. Hasil Cor Baling-Baling Kapal Nelayan Setelah Proses Pemeriksaan Visualisasi

Sumber: IKM Pengecoran Desa Mayangan Kecamatan Panggungrejo Kota Pasuruan

Baling-baling (propeller) merupakan salah satu komponen yang dipasang pada kapal nelayan yang digerakkan oleh motor diesel sebagai penggerak mula. Prinsip kerja motor diesel menggerakkan baling-baling melalui kopling dan poros baling-baling, sehingga balingbaling berputar menghasilkan gaya dorong maju atau mundur (Gambar 7).

Gaya dorong yang ditimbulkan oleh putaran baling-baling ditransmisikan ke kopling melalui poros baling-baling dan thrust bearing, sehingga kopling atau motor diesel akan terdorong, karena kopling atau motor diesel menyatu dengan kapal melalui engine bed, maka kapalnya akan bergerak (http://wwwbalaidiklatperikanan. blogspot.com/2016/).

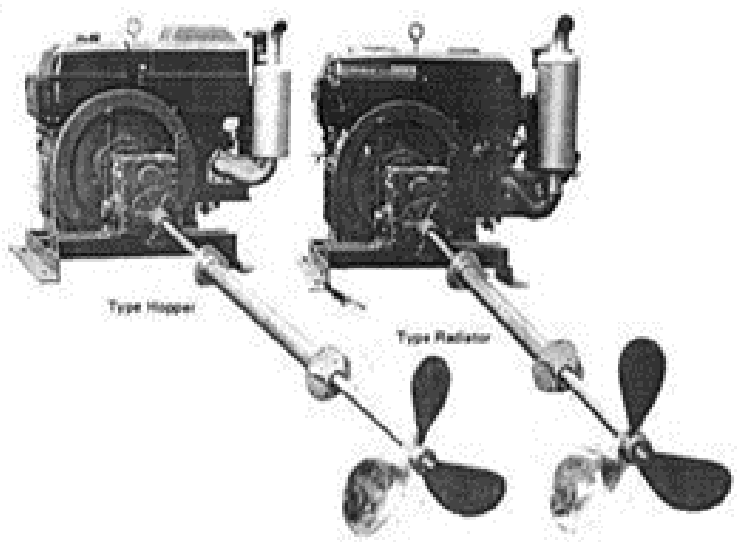

Gambar 7. Motor Diesel Sebagai Penggerak Baling-Baling

Sumber:https://farichaputri1996.wordpress.com/ 2014/03/26/bab-2-klasifikasi-kapal/

Motor diesel pada kapal nelayan umumnya dilengkapi dengan beberapa elemen pendukung seperti: 
1. Kopling berfungsi untuk:

a. Pemutus hubungan antara putaran mesin dengan poros baling-baling.

b. Penghubung putaran mesin dengan poros baling-baling.

c. Pembalik arah putaran poros baling-baling agar kapal dapat bergerak maju atau mundur.

d. Reduktor (mereduksi) putaran mesin untuk keseimbangan torsi pada mesin dengan baling-baling.

2. Rangka mesin berfungsi untuk menerima dan meneruskan gaya dorong dari baling-baling ke kapal.

3. Thrust bearing), dipasang di poros utama kopling berfungsi untuk:

a. Mendukung poros utama kopling dan poros baling-baling.

b. Menahan gaya dorong dari baling-baling dan meneruskan ke kopling, sehingga gaya dorong tersebut, tidak merusak komponenkomponen mesin yang bergarak.

4. Komponen-komponen mesin yang tahan terhadap air laut, terutama pada bagian-bagian yang berhubungan dengan sistem pendinginan mesin.

b. Permasalahan yang Dihadapi IKM Pengecoran Desa Mayangan Kecamatan Panggungrejo Kota Pasuruan

Bimbingan teknis (bimtek) bagi IKM Pengecoran Desa Mayangan Kecamatan Panggungrejo Kota Pasuruan merupakan kegiatan yang dilaksanakan oleh Disperindag Kota Pasuruan bekerjasama dengan Jurusan Teknik Mesin Fakultas Teknik Universitas Merdeka Malang (Gambar 8). Berdasarkan hasil ceramah dan diskusi dengan IKM logam produk baling-baling kapal dapat diidentifikasi beberapa permasalahan meliputi: (a) cacat rongga udara disebabkan oleh penggunaan model cawan tuang dan saluran turun yang langsung (conical basin) digunakan pada cetakan pasir, dan (b) udara atau gas dari cetakan pasir atau logam cair skrap aluminium tidak dapat keluar melalui rongga antara butir-butir pasir saat proses penuangan, dan (c) pasir sungai berbentuk butir pasir kristal yang dapat mempengaruhi ketahanan api dan permeabilitas yang rendah pada cetakan pasir akibatnya membutuhkan pengikat dalam jumlah banyak, dan (d) kadar air pada pasir sungai untuk pembuatan cetakan pasir kurang dari 1,5\% - 8\% akibatnya lempung akan mengalami kekurangan daya ikat pada pasir.

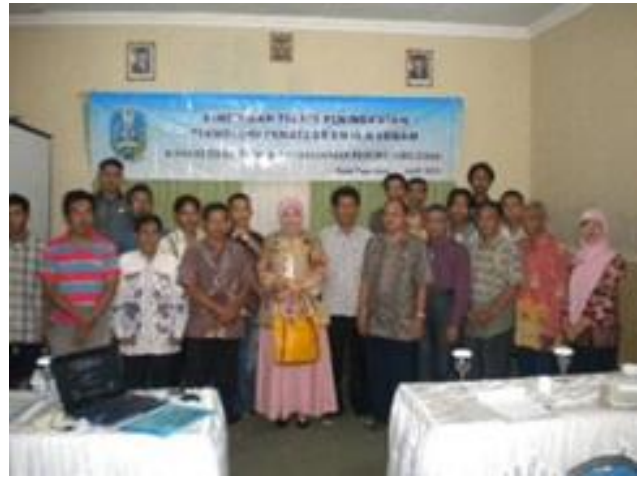

Gambar 8. Peserta Bimtek

Sumber: Disperindag Kota Pasuruan

\section{METODE KEGIATAN}

Bimbingan teknis (bimtek) (Andrijono, R. D., Sufiyanto, S., 2018) merupakan kegiatan pengabdian kepada masyarakat sebagai implementasi dari salah satu tri darma perguruan tinggi yang berlokasi di IKM Pengecoran Desa Mayangan Kecamatan Panggungrejo Kota Pasuruan. Sebelum bimtek dimulai dilakukan acara pembukaan oleh Kepala Disperindag Kota Pasuruan dengan didampingi perwakilan dari Disperindag Provinsi Jawa Timur (Gambar 9).

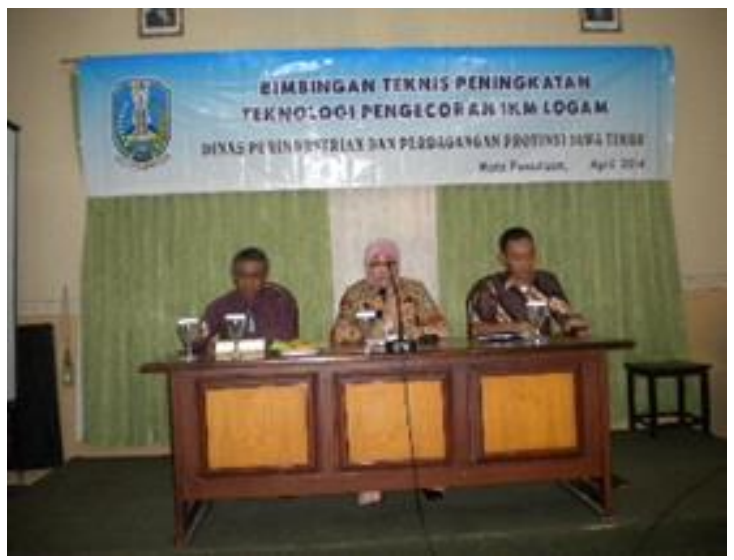

Gambar 9. Acara Pembukaan oleh Kepala Disperindag Kota Pasuruan

Sumber: Disperindag Kota Pasuruan

Kegiatan bimtek yang dilakukan menggunakan 2 (dua) metode meliputi: metode ceramah dan metode diskusi.

a. Metode Ceramah

Metode ceramah (preaching method) merupakan metode penyampaian materi penyuluhan bersifat kognitif kepada peserta bimtek (Gambar 10). Kognitif diartikan potensi intelektual meliputi: pengetahuan (knowledge), pemahaman (comprehention), penerapan (aplication), analisa (analysis), sintesa (sinthesis), evaluasi (evaluation).

Materi penyuluhan bersifat kognitif meliputi: proses pengecoran, pemilihan pasir 
cetak, sifat-sifat pasir cetak, proses pembuatan pola, proses pembuatan cetakan pasir, sifat-sifat logam cor, cacat cor, sistem pemeriksaan hasil cor, dan proses pengerjaan akhir.

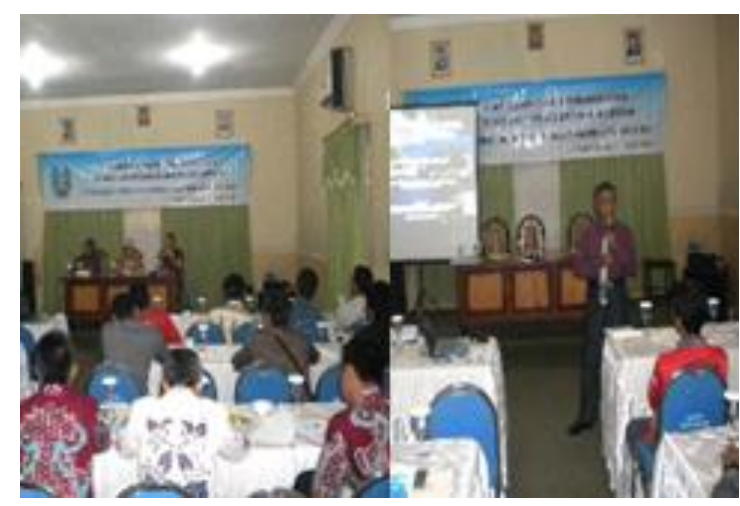

Gambar 10. Metode Ceramah Bagi Peserta Bimtek Sumber: Disperindag Kota Pasuruan

b. Metode Diskusi

Metode diskusi (discussion method) merupakan metode yang sangat erat hubungannya dengan pemecahan masalah (problem solving). Metode ini lazim disebut sebagai diskusi kelompok (group discussion) dan resitasi bersama (socialized recitation). Metode tersebut, dilakukan setelah selesai penyampaian materi melalui metode ceramah (Gambar 11).

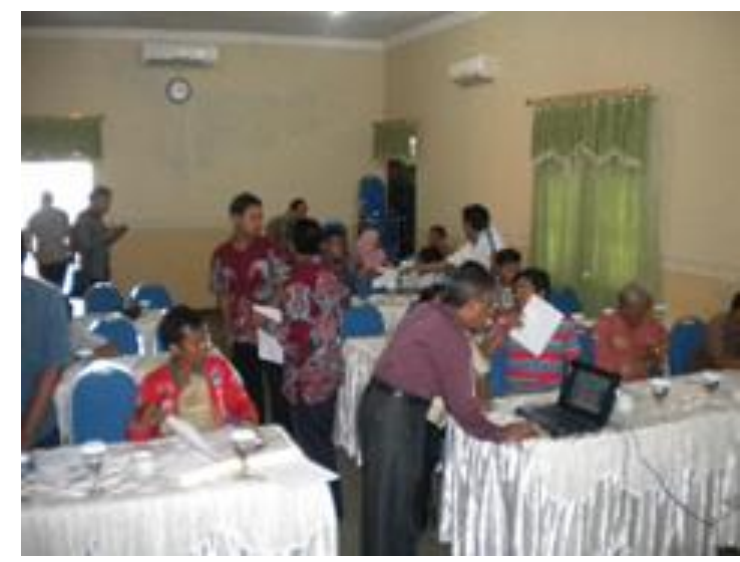

Gambar 11. Metode Diskusi Bagi Peserta Bimtek Sumber: Disperindag Kota Pasuruan

\section{HASIL DAN PEMBAHASAN}

Program pengabdian kepada masyarakat melalui bimtek yang dilaksanakan oleh Disperindag Kota Pasuruan bekerjasama dengan Jurusan Teknik Mesin Fakultas Teknik Universitas Merdeka Malang diharapkan dapat meningkatkan pengetahuan dan ketrampilan bagi IKM Pengecoran desa Mayangan Kecamatan Panggungrejo Kota Pasuruan untuk memproduksi baling-baling kapal nelayan dengan proses pengecoran menggunakan cetakan pasir (sand casting) dan bahan dasar jenis skrap aluminium (aluminium scrap) (Gambar 1). Di samping hal tersebut, kegiatan bimtek diharapkan berdampak pada daya saing di pasar lokal dan nasional serta dapat meningkatkan pendapatan bagi IKM Pengecoran desa Mayangan Kecamatan Panggungrejo Kota Pasuruan.

Cetakan yang digunakan untuk pembuatan baling-baling kapal nelayan menggunakan cetakan pasir, karena mempunyai keuntungan meliputi: (a) harga pasir cetak murah dibanding dengan logam, (b) pasir cetak dapat dipakai secara berulang-ulang, (c) mampu digunakan untuk produksi masal (mass production), dan (d) cetakan bersifat fleksibel untuk digunakan membuat produk cor dengan bentuk yang sederhana dan rumit, sedangkan kerugiannya meliputi: (a) hasil cor mudah cacat, (b) permukaan hasil cor kasar, (c) hasil cor tidak presisi, (d) produksi masal diperlukan cetakan yang banyak, dan (e) produk cor diperlukan proses pengerjaan akhir (finishing) seperti: gerinda, gergaji.

Secara teoritis cetakan pasir (sand casting) dapat disebut juga dengan istilah cetakan sekali pakai (expendable mold) atau non permanen artinya untuk proses pengambilan hasil cor dengan cara merusak cetakan pasir (G.J. Davies, 1973). Pengecoran cetakan pasir memberikan fleksibilitas dan kemampuan tinggi dibanding cetakan logam.

Cetakan pasir dibuat dengan memadatkan pasir dan pasir yang dipakai biasanya pasir alam atau pasir buatan yang mengandung tanah lempung atau kadang-kadang dicampur pengikat khusus seperti: (a) air-kaca, (b) semen, (c) resin furan, (d) resin fenol atau minyak pengering. Logam yang dapat dituang pada cetakan pasir adalah besi, baja, tembaga, perunggu, kuningan, aluminium ataupun logam paduan (Arianto Leman Soemowidagdo, 2016).

Bahan cetakan yang digunakan IKM Pengecoran Desa Mayangan Kecamatan Panggungrejo Kota Pasuruan menggunakan pasir cetak. Syarat-syarat pasir cetak secara umum (http://infoletters.blogspot.com/2011/04/) syaratsyarat-pasir-cetak-dalam.html) meliputi:

1. Kemampuan pembentukan

Sifat ini memungkinkan pasir cetak dapat mengisi semua sisi dan ujung dari pola, sehingga dapat menjaga hasil cor memiliki ukuran yang benar.

2. Plastisitas

Dapat bergerak naik dan turun mengisi rongga-rongga yang kosong. 
3. Kekuatan basah

Kekuatan basah menentukan cetakan tidak hancur atau rusak saat diisi dengan logam cair atau saat cetakan dipindah dari tempat yang satu ke tempat yang lain.

4. Kekuatan kering

Kekuatan kering diperlukan pada saat cetakan mengering karena perpindahan panas dengan logam cair.

\section{Permeabilitas}

Kemampuan cetakan pasir untuk melepaskan udara dan gas panas dari dalam cetakan selama pelaksanaan proses pengecoran melalui celah-celah pasir cetak.

6. Tahan terhadap temperatur logam cair selama proses penuangan logam cair ke dalam cetakan pasir.

Pasir cetak yang digunakan IKM

Pengecoran Desa Mayangan Kecamatan Panggungrejo Kota Pasuruan adalah jenis pasir sungai (Gambar 12). Pasir sungai merupakan salah satu varian yang berasal dari sungai dengan diameter 0,063 - $5 \mathrm{~mm}$ dan bahan utama pembentuk pasir meliputi: silikon dioksida serta batuan kapur (https://indonusa-conblock.com/ pengertian-dan-manfaat-pasir-sungai/, Banga, TR, 1981).

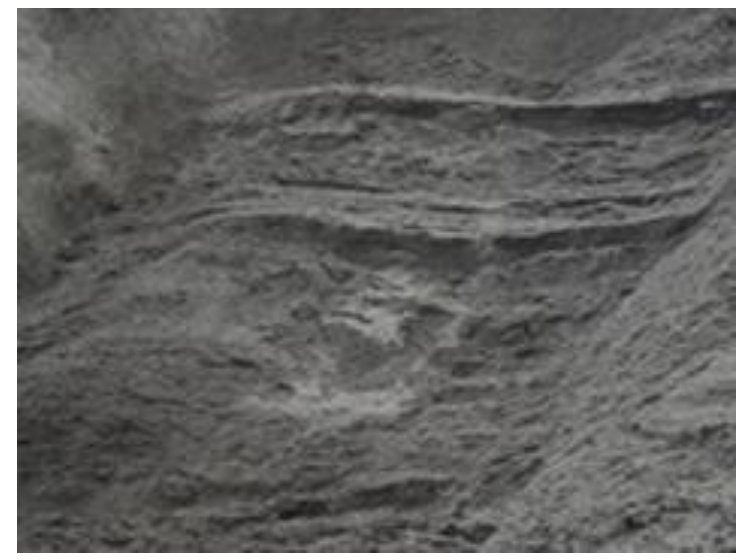

Gambar 12. Pasir Sungai

Sumber: https://indonusa-conblock.com/pengertian-danmanfaat-pasir-sungai

Pasir sungai merupakan jenis pasir berasal dari proses penggalian di sungai. Sungai-sungai yang terjal memiliki aliran yang deras, sehingga deposit dari partikel batu-batuannya akan bervariasi cukup besar pada suatu jarak tertentu, biasanya butir halusnya tidak banyak dan batuanbatuannya cukup bersih. Pada sungai-sungai yang landai, variasi perbedaan ukuran partikel tidak berubah dari tempat yang satu ke tempat yang lain, umumnya partikel-partikelnya lebih bulat dan kotor. (http://eprints.ums.ac.id/48276/5/ BAB\%20I.pdf).

Bahan dasar untuk membuat baling-baling kapal nelayan oleh IKM Pengecoran Desa Mayangan Kecamatan Panggungrejo Kota Pasuruan menggunakan skrap aluminium (Gambar 1). merupakan salah satu jenis logam bukan besi (http://teknologikimiaindustri. blogspot.com/2010/12/aluminium.html) dan sifat-sifat aluminium (Tabel 3).

Tabel 3. Sifat-Sifat Aluminium

\begin{tabular}{|c|c|c|}
\hline No & Sifat & Keterangan \\
\hline 1 & Titik lebur & Aluminium mempunyai titik lebur $660{ }^{\circ} \mathrm{C}$ \\
\hline 2 & Titik didih & Aluminium mempunyai titik didih $2452{ }^{\circ} \mathrm{C}$ \\
\hline 3 & $\begin{array}{l}\text { Kekuatan } \\
\text { tarik }\end{array}$ & $\begin{array}{l}\text { Aluminium mempunyai kekuatan tarik } 4,76 \\
\mathrm{~kg} / \mathrm{mm}^{2}\end{array}$ \\
\hline 4 & $\begin{array}{l}\text { Anti } \\
\text { magnetis }\end{array}$ & Aluminium adalah logam yang anti magnetis \\
\hline 5 & Ringan & $\begin{array}{l}\text { Massa jenis } 2,7 \mathrm{gram} / \mathrm{cm}^{3} \text { pada temperatur } \\
\text { kamr } 29^{0} \mathrm{C} \text { dan } 2,368 \mathrm{gr} / \mathrm{cm}^{3} \text { pada } \\
\text { temperatur } 660^{\circ} \mathrm{C}\end{array}$ \\
\hline & & $\begin{array}{l}\text { Aluminium mempunyai regangan } 8 \mathrm{~kg} / \mathrm{mm}^{3} \\
\text { regangan dapat berubah menjadi }\end{array}$ \\
\hline 6 & Kuat & $\begin{array}{l}\text { lebih kuat dua kali lipat apabila aluminium } \\
\text { dilakukan proses paduan seperti: } \mathrm{Mg}, \mathrm{Zn} \\
\mathrm{Mn}, \mathrm{Si} \text { atau proses pengerolan }\end{array}$ \\
\hline 7 & $\begin{array}{l}\text { Tahan } \\
\text { korosi }\end{array}$ & $\begin{array}{l}\text { Aluminium mempunyai sifat tahan koros } \\
\text { karena terdapat lapisan aluminium oksida } \\
\left(\mathrm{Al}_{2} \mathrm{O}_{3}\right) \text { yang tipis dan sangat keras. }\end{array}$ \\
\hline 8 & $\begin{array}{l}\text { Mampu } \\
\text { bentuk }\end{array}$ & $\begin{array}{l}\text { Aluminium mempunyai sifat yang baik } \\
\text { untuk proses mekanik dari kemampuan } \\
\text { perpanjangannya, hal ini dapat dilihat dar } \\
\text { proses penuangan, pemotongan } \\
\text { pembengkokan, ekstrusi dan penempaan }\end{array}$ \\
\hline 9 & Toksifitas & $\begin{array}{l}\text { Aluminium mempunyai sifat tidak beracun } \\
\text { dan tidak berbau. }\end{array}$ \\
\hline 10 & $\begin{array}{l}\text { Sifat dapat } \\
\text { dipakai } \\
\text { kembali }\end{array}$ & $\begin{array}{l}\text { Aluminium mempunyai titik lebur yang } \\
\text { rendah, sehingga dapat memperoleh kembal } \\
\text { logam Aluminium dari scrap. }\end{array}$ \\
\hline 11 & $\begin{array}{l}\text { Nomor } \\
\text { atom }\end{array}$ & 13 \\
\hline 12 & $\begin{array}{l}\text { Massa atom } \\
\text { relatif }\end{array}$ & 26,98 \\
\hline
\end{tabular}

Sumber: Avner, 1974, G.J . Davies, 1973

Pemecahan masalah yang dihadapi IKM Pengecoran Desa Mayangan Kecamatan Panggungrejo Kota Pasuruan yang diuraikan di atas meliputi:

Pertama, produk cor yang dihasilkan oleh IKM Pengecoran Desa Mayangan Kecamatan Panggungrejo Kota Pasuruan terdapat cacat rongga udara, sehingga mempengaruhi mutu produk cor baling-baling kapal nelayan (Gambar 13). 


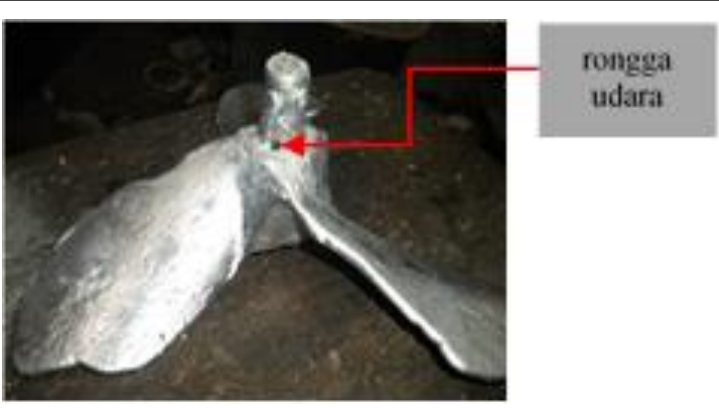

Gambar 13. Cacat Rongga Udara Sumber: IKM Pengecoran Desa Mayangan Kecamatan Panggungrejo Kota Pasuruan

Cacat rongga udara disebabkan oleh aliran logam cair skrap aluminium mengalami turbulensi saat dituang ke dalam cetakan pasir, akibatnya udara terperangkap di dalam logam cair skrap aluminium (G.J. Davies, 1973, C.W. Ammien, 1979, Tata Surdia, 2000).

Untuk mengatasi permasalahan tersebut, dapat dilakukan dengan mengubah aliran logam cair skrap aluminium tidak terjadi secara turbulensi dengan menerapkan saluran tuang tipe offset stepped basin yang diharapkan agar aliran logam cor skrap aluminium terjadi aliran laminar, sehingga cacat rongga udara dapat diminimalisir (Gambar 14).

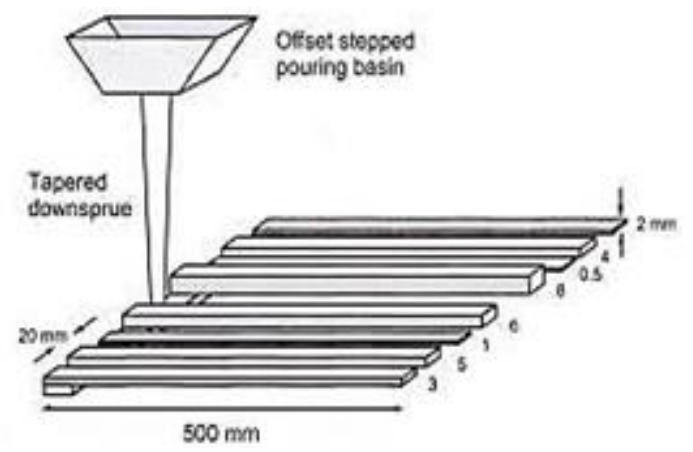

Gambar 14. Saluran Tuang Model Offset Stepped Basin

Sumber: Sugeng Slamet, 2017

Kedua, udara atau gas panas yang berasal dari cetakan pasir atau logam cair skrap aluminium tidak dapat keluar melalui rongga antara butir-butir pasir saat proses penuangan (Sujana Lingga, 2018). Cetakan pasir memenuhi syarat untuk dipakai apabila mempunyai permeabilitas yang cocok dengan karakteristik logam cair yang dituang dan permeabilitas pada cetakan pasir juga dipengaruhi oleh bahan pengikat (binder) (Caliari, D et al., 2015). Bahan pengikat tersebut, akan berpengaruh juga pada permeabilitas pasir cetak.

Bahan pengikat yang digunakan pada cetakan pasir antara lain: lempung (bentonit), semen, water glass, dan resin (Tata Surdia, 2000, Caliari, D et al., 2015). Untuk mengatasi permasalahan tersebut, pasir sungai perlu dilakukan pengujian permeabilitas dengan tujuan untuk menganalisa kemampuan pasir sungai untuk dapat dilewati udara atau gas panas diantara butir-butir pasir (Tata Surdia, 2000). Prosedur melakukan pengujian permeablitas diawali membuat spesimen standar berukuran diameter $50 \mathrm{~mm}$ x $50 \mathrm{~mm}$ dengan memadatkan pasir dalam silinder pemadat dari ukuran tertentu sebanyak 3 kali oleh pemadat pasir yang standar. Selanjutnya spesimen dipasang pada alat uji permeabilitas (Gambar 15) dan pengujian dilakukan dengan perbedaan tekanan serta waktu yang diperlukan untuk melewatkan $2000 \mathrm{~cm}^{3}$ melalui spesimen standar. Permeabilitas dihitung dengan rumus (Tata Surdia, 2000, http://staffnew.uny.ac.id/upload/132048523/pend idikan/5.+Pasir+cetak.pdf):

$$
P=\frac{Q \cdot L}{p \cdot A \cdot T}\left(\mathrm{ml} / \mathrm{cm}^{2}\right)
$$

di mana:

$P=$ permeabilitas $\left(\mathrm{ml} / \mathrm{cm}^{2}\right)$

$Q=$ volume udara yang lewat melalui spesimen $\left(\mathrm{cm}^{3}\right)$

$L=$ panjang spesimen $(5 \mathrm{~cm})$.

$A=$ luas irisan $\left(19,625 \mathrm{~cm}^{2}\right)$

$P=$ tekanan udara $(\mathrm{cm})$.

$T=$ waktu yang diperlukan untuk melewatkan volume udara $Q$ melalui spesimen.

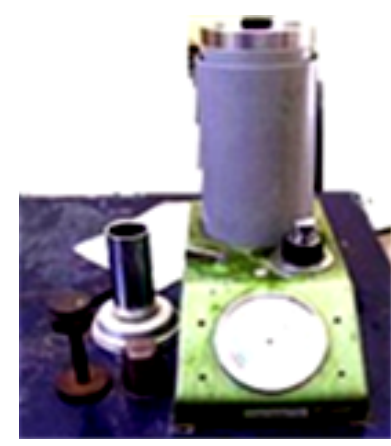

Gambar 15. Mesin Uji Permeabilitas Sumber:http://staffnew.uny.ac.id/upload/132048523/pendidi kan/5.+Pasir+cetak.pdf

Ketiga, pasir sungai berbentuk butir pasir kristal dapat mempengaruhi ketahanan api dan permeabilitas yang rendah pada cetakan pasir, akibatnya membutuhkan pengikat dalam jumlah banyak (Gambar 16). Untuk mengatasi permasalahan tersebut, dengan cara mengganti pasir sungai berbentuk butir pasir bulat (round sand) (Gambar 17) yang bertujuan agar kebutuhan pengikat lebih rendah, sehingga 
diperoleh kekuatan dan permeabilitas serta mampu alirnya (flowability) yang optimum (Tata Surdia, 2000, Banga, TR, 1981).
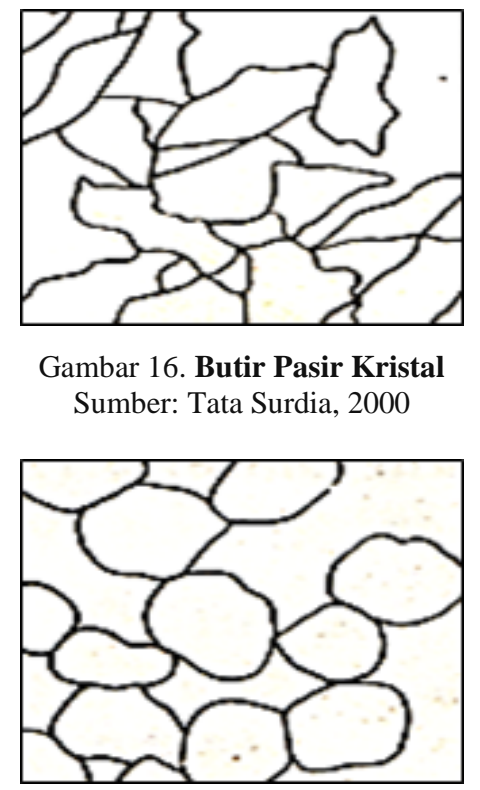

Gambar 17. Butir Pasir Bulat Sumber: Tata Surdia, 2000

Keempat, kadar air pada pasir sungai untuk pembuatan cetakan pasir kurang dari 1,5\% - 8\% akibatnya lempung pada pasir sungai akan kekurangan daya ikat untuk mengikat pasir. Untuk mengetahui kadar air pada sungai perlu dilakukan uji kadar. Untuk melakukan uji kadar air dibutuhkan alat uji kadar air (Gambar 18). Alat bantu lainnya adalah timbangan berat. Kadar air dalam pasir cetak kering antara $2 \%$ s.d $12 \%$. Prosedur uji kadar air pada pasir sungai meliputi beberapa tahap: (a) timbang campuran pasir awal 50 gram, (b) keringkan spesimen dalam tungku pengering pada suhu $110^{\circ} \mathrm{C}$ selama 1 jam, (c) kemudian spesimen didinginkan dengan desikator, (d) timbang kembali berat campuran pasir, dan (e) hitung perbedaan berat awal dan akhir dalam satuan prosentase sebagai kadar air bebas dalam pasir sungai. Kadar air dihitung dengan rumus (Tata Surdia, 2000, http://staffnew.uny.ac.id/upload/132048523/pend idikan/5.+Pasir+cetak.pdf).

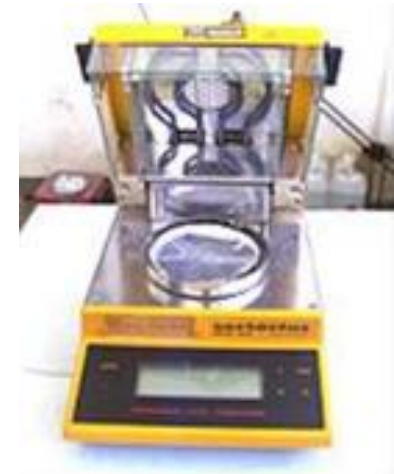

Gambar 18. Mesin Uji Kadar Air Sumber:http://staffnew.uny.ac.id/upload/132048523/pen didikan/5.+Pasir+cetak.pdf

Kadar air $=\frac{\text { berat spesimen }(\text { gram })-\text { berat pasir sisa }(\text { gram })}{\text { berat spesimen }(\text { gram })} \times 100 \%$

\section{KESIMPULAN}

a. Cacat rongga udara dapat dikurangi dengan memasang saluran tuang tipe offset stepped basin agar tidak terjadi turbulensi saat penuangan logam cair skrap aluminium.

b. Meningkatkan permeabilitas pasir sungai agar udara atau gas panas berasal dari cetakan pasir atau logam cair skrap aluminium dapat keluar melalui rongga antara butir-butir pasir saat proses penuangan logam cair.

c. Butir pasir sungai yang digunakan berbentuk bulat agar kebutuhan pengikat lebih rendah, sehingga diperoleh kekuatan dan permeabilitas serta mampu alir yang optimun.

d. Meningkatkan kadar air pada pasir sungai untuk pembuatan cetakan pasir lebih dari $1,5 \%-8 \%$ agar lempung tidak mengalami kekurangan daya ikat untuk mengikat pasir sungai.

\section{DAFTAR PUSTAKA}

Andrijono, R. D., Sufiyanto, S., 2018, Bimbingan Teknis Desain Dapur Pemanas Model Tertutup Dan Cerobong Ganda Pada Manajemen Bisnis Ukm Pandai Besi Wilayah Disperindag Kabupaten Malang, Abdimas, Vol. 3 No. 1, Hal. 32-40, Universitas Merdeka Malang

Arianto Leman Soemowidagdo, 2016, Bahan Pada Pengecoran Logam, Sumber Belajar Penunjang PLPG Mata Pelajaran/Paket Keahlian Teknik Pengecoran Logam. Kementerian Pendidikan dan Kebudayaan Direktorat Jenderal Guru dan Tenaga Kependidikan. 
Banga, T.R. 1981. Foundry Engineering, Surdia Tata, 2000. Teknik Pengecoran Logam. Khanna Publishers, New Delhi. Jakarta: PT. Pradnya Paramita.

C.W. Ammien, 1979. The Complete Handbook of Sand Casting. First Edition. Printed in the USA.

Caliari, D et al., 2015. Fluidity Of Aluminium Foundry Alloys: Development Of A Testing Procedure. Metallurgia Italiana, 107(6).

diskopukm.jatimprov.go.id/viewmedia.php?page $\mathrm{s}=$ content

Dispenduk Capil Kota Pasuruan, 2017.

G.J. Davies, 1973. Solidification and Casting, Applied Science Publishers, LTD. London.

Harmanto, S. 2012. Pengaruh Tebal Coran pada Proses HDPC terhadap Porositas Dengan Material ADC 12. Orbit Volume. 8 No. 2 Juli 2012: 94 - 97.

http://eprints.ums.ac.id/48276/5/BAB\%20I.pdf

http://mohammadfachrii.blogspot.com/2017/03/p rofil-kota-pasuruan-jawa-timur.html

http://teknologikimiaindustri.blogspot.com/2010/ 12/aluminium.html

http://wwwbalaidiklatperikanan.blogspot.com/20 $16 /)$.

https://farichaputri1996.wordpress.com/

https://id.wikipedia.org/wiki/Kota_Pasuruan.

https://indonusa-conblock.com/pengertian-danmanfaat-pasir-sungai

https://pasuruankota.go.id/geografi/

http://staffnew.uny.ac.id/upload/132048523/pend idikan/5.+Pasir+cetak.pdf

Sugeng Slamet, 2017. Pengaruh Komposisi dan Temperatur Ruang terhadap Fluiditas Paduan Perunggu Timah Melalui Investment Casting. Prosiding SNATIF Ke 4 ISBN: 978-602-1180-50-1 Fakultas Teknik Universitas Muria Kudus.

Sujana Lingga, 2018. Pengaruh Permeabilitas Cetakan Pasir dan Temperatur Tuang pada Proses Pengecoran Aluminium Silikon (Al7\% Si) terhadap Kekuatan Tarik, Kekerasan dan Struktur Mikro. Jurnal Ilmiah Teknik Desain Mekanika Vol. 7 No. 1, Januari 2018 (39 - 44) Program Studi Teknik Mesin Universitas Udayana, Kampus Bukit Jimbaran Bali 